\title{
Effects of Triacylglycerol Molecular Species on the Oxidation Behavior of Oils Containing $\alpha$-Linolenic Acid
}

\author{
Shinsuke Dote ${ }^{1}$, Yukihiro Yamamoto ${ }^{1,2 *}$ and Setsuko Hara ${ }^{1}$ \\ ${ }^{1}$ Faculty of Science and Technology, Seikei University, 3-3-1 Kichijoji-kitamachi, Musashino, Tokyo 180-8633, JAPAN \\ ${ }^{2}$ Present address, Faculty of Life and Environmental Science, Prefectural University of Hiroshima, 562 Nanatsuka-cho, Shobara, Hiroshima, \\ 727-0023, JAPAN
}

\begin{abstract}
Two kinds of oils, pure perilla oil and a blend of perilla oil with palm oil, and their enzymatically interesterified oils having the same fatty acid compositions but with different compositions of triacylglycerol (TAG) species, were studied. In particular, the effects of TAG molecular species on the oxidation resistance of oils containing $\alpha$-linolenic acid $(L n)$ were investigated. The content of TAG binding to three $\mathrm{Ln}$ molecules (3Ln-TAG) was found to be different between perilla oil (38.7\%) and the interesterified oils (14.5-28.9\%), which were generated using Lipozyme RM-IM ${ }^{\circledR}$ (regiospecificity: sn-1, 3 positional). Oils with lower $3 \mathrm{Ln}-$ TAG contents were more stable to oxidation as determined by the conductometric determination method $\left(\mathrm{CDM} ; 90^{\circ} \mathrm{C}, 20 \mathrm{~L} / \mathrm{h}\right)$ than oils with higher $3 \mathrm{Ln}-\mathrm{TAG}$ contents. This result was also supported by heating oxidation tests $\left(180^{\circ} \mathrm{C}, 7 \mathrm{~h}\right)$ using the interesterified blended oils; the residual ratio of Ln-TAGs in the oils was found to be in the order of $3 \mathrm{Ln}-\mathrm{TAG}<2 \mathrm{Ln}-\mathrm{TAG}<1 \mathrm{Ln}$-TAG. Oxidation stability of Lipase $\mathrm{OF}^{\circledR}$ (regiospecificity: random)-interesterified blended oils also improved on lowering the 3Ln-TAG content. In addition, the oxidation stabilities of Lipozyme RM-IM ${ }^{\circledR}$-interesterified oils were slightly higher than those of the Lipase $\mathrm{OF}^{\circledR}$-interesterified oils. We found that the content of $3 \mathrm{Ln}$-TAG was almost the same in both oils, and the content of unsaturated fatty acid at the $s n-1,3$ positions of Lipase $O F^{\circledR}$-interesterified oils was higher than that of Lipozyme RM-IM ${ }^{\circledR}$-interesterified oils. These results indicate that oxidation stabilities of oils containing TAG with unsaturated fatty acid such as $\mathrm{Ln}$ at $\mathbf{s n - 2}$ position were higher than those having unsaturated fatty acids at the $s n-1,3$ positions. From these results, the oxidation stability of oils rich in Ln, such as perilla oil and linseed oil, can be improved not only by decreasing $3 \mathrm{Ln}$-TAG but also by enzymatically reducing the unsaturated fatty acid content at the $s n-1,3$ positions.
\end{abstract}

Key words: oxidation behavior, triacylglycerol molecular species, $\alpha$-linolenic acids, perilla oil

\section{INTRODUCTION}

Linolenic acid (Ln) (C18:3 n-3) is found in high concentration in both perilla oil $(\mathrm{ca} .64 \%)^{1)}$ and linseed oil (ca. $60 \%)^{2)}$ and is an essential fatty acid for humans. Because $\mathrm{Ln}$ is a substrate for $\Delta 6$-desaturase and elongase, $\mathrm{Ln}$ is a precursor molecule for eicosapentaenoic acid synthesis and related eicosanoids (e.g., prostaglandin 3 and the leukotriene 5 series). Chung et al. studied the cardioprotective effect of perilla oil and linseed oil, and they reported an increase of in the concentrations of both eicosapentaenoic acid (EPA) and docosahexaenoic acid (DHA) in the plasma of mice fed with perilla and linseed oils ${ }^{3}$. Because linoleic acid (C18:2 n-6, another essential fatty acid) -derived eicosanoids (prostaglandin 1,2 and leukotriene 4 series) exert antagonistic effects on Ln-derived eicosanoids, balancing the intake of these fatty acids is very important for human health; in recent years, a low intake of n-3 unsaturated fatty acids such as Ln, EPA and DHA has been shown to be a problem, especially in developed countries.

A significant problem is that $\mathrm{Ln}$ is sensitive to oxidation. Therefore, for better storage and use, the oxidation stability of highly unsaturated oils must be improved. Oxidative stability of oils has known to be affected by their TAG molecular species composition ${ }^{4-10)}$. In 1983, Wada et al. showed that oxidative the stability of TAG with unsaturat-

\footnotetext{
*Correspondence to: Yukihiro Yamamoto, Faculty of Life and Environmental Science, Prefectural University of Hiroshima, 562 Nanatsuka-cho, Shobara, Hiroshima, 727-0023, JAPAN

E-mail: yyamamoto@ pu-hiroshima.ac.jp

Accepted December 17, 2015 (received for review November 24, 2015)

Journal of Oleo Science ISSN 1345-8957 print / ISSN 1347-3352 online

http://www.jstage.jst.go.jp/browse/jos/ http://mc.manusriptcentral.com/jjocs
} 
ed fatty acids at the $s n-2$ position was greater than those having fatty acids at the $s n-1$ (3) position, as determined by comparison of the oxidation rates of interesterified TAGs prepared from tripalmitin, tristearin, triolein, and trilinole$\mathrm{in}^{4)}$. Marine oils such as whale, sardine, cod liver, and skipjack oils were subjected to Lipase TOYO $^{\circledR}$ mediated interesterification, and all, except whale oil, had higher oxidation stabilities after interesterification: this is due to the reduction in the content of highly unsaturated TAG that occurs on interesterification ${ }^{5)}$. For polyunsaturated fatty acids, Chakra et al. reported that the oxidation stabilities of TAGs having DHA at the sn-2 position were higher those at the $s n-1(3)$ position $^{6)}$. Recently, we have reported that TAG containing conjugated linolenic acid is stable when located at the $s n-2$ position in the TAG molecule ${ }^{7)}$. However, there is little research focused on the effects of triacylglycerol molecular species on the oxidation behavior of oils containing Ln. For example, Frankel and coworkers reported that $2 \mathrm{Ln}$-TAGs are less stable to oxidation when $\mathrm{Ln}$ is at the $s n-1,2$ (or $-2,3$ ) position compared to the $s n-1,3$ glycerol positions as determined by autoxidation tests ${ }^{9,10)}$.

In this study, we first prepared interesterified oils from perilla oil - Egoma yu in Japanese - and its blended oil with palm oil using either the $s n-1,3$ positional specific Lipozyme RM-IM ${ }^{\circledR}$ or non-specific Lipase $\mathrm{OF}^{\circledR}$ to obtain oils having the same fatty acid composition but with different compositions of TAG species. Then, the relation between the oxidation stability of oils rich in Ln and TAG molecular species composition was investigated by evaluating their oxidation stability based on $\operatorname{CDM}\left(90^{\circ} \mathrm{C}, 20 \mathrm{~L} / \mathrm{h}\right)$ and heating stability tests $\left(180^{\circ} \mathrm{C}, 7 \mathrm{~h}\right)$. In addition, the fatty acid composition at the $s n-2$ position and compositions of TAG molecular species were analyzed.

\section{EXPERIMENTAL}

\subsection{Materials}

Commercially available Perilla oil was used(Benibana Foods Co., Ltd., Tokyo). Palm oil was donated by Miyoshi Oil \& Fat Co., Ltd., (Tokyo). Lipozyme RM-IM ${ }^{\circledR}$ (Rhizomucor miehei, $150 \mathrm{IUN} / g$, regiospecificity: sn-1,3 positional) and Novozym $435^{\circledR}$ (Candida antarctica, 10,000 PLU/g, regiospecificity: random) were purchased from Novozymes (Bagsværd, Denmark). Lipase $\mathrm{OF}^{\circledR}$ (Candida cylindracea, 360,000 U/g, regiospecificity: random) was purchased from Meito Sangyo Co., Ltd(Aichi, Japan). Other reagents and solvents were of analytical grade.

\subsection{Preparation of interesterified oils}

Oils (5 g of perilla oil, Ln2:1 or Ln1:1) were dissolved in hexane $(20 \mathrm{~mL})$ and Lipozyme RM-IM ${ }^{\circledR}$ or Lipase $\mathrm{OF}^{\circledR}(0.75$ g) was added to begin the interesterification process. The samples were agitated at $500 \mathrm{rpm}$ and held at either $60^{\circ} \mathrm{C}$ (for Lipozyme RM-IM ${ }^{\circledR}$ ) or $40^{\circ} \mathrm{C}$ (for Lipase $\mathrm{OF}^{\circledR}$ ) during the reaction. Enzymes were filtered through filter paper to end the reaction, and the filtrate was evaporated to obtain the reaction mixture. The interesterified oil was fractionated by silica gel column chromatography with an hexane-diethyl ether $(85: 15, \mathrm{v} / \mathrm{v})$ eluent to separate trace amounts of free fatty acids, diacylglycerols (DAG), monoacylglycerols (MAG) and tocopherols from the reaction mixture. The reaction times required to prepare the interesterified blended oils using Lipozyme RM-IM ${ }^{\circledR}$ and lipase $\mathrm{OF}^{\circledR}$ were 4 and $48 \mathrm{~h}$, respectively.

\subsection{Oxidation samples}

For oxidation, different kinds of Ln containing oils were used. Perilla and palm oils were mixed at $2: 1$ or $1: 1(\mathrm{w} / \mathrm{w})$ ratios, labeled as $\operatorname{Ln} 2: 1$ and $\operatorname{Ln} 1: 1$, respectively. Interesterification of perilla oil was carried out using Lipozyme RM-IM ${ }^{\circledR}$ with different reaction times, allowing preparation of samples P-1 (16 h), P-2 (8h), and P-3 (24 h). In addition, the blended oils of perilla and palm oils were prepared using either Lipozyme RM-IM ${ }^{\circledR}\left(4\right.$ h) or Lipase $\mathrm{OF}^{\circledR}(48$ h), respectively.

\subsection{Evaluation of the oxidation stability of oils based on CDM tests}

The oxidation stabilities of perilla oil, Ln2:1, Ln1:1 and their interesterified oils were evaluated by CDM in accordance with the standard method for the analysis of fats, oils and related materials as prescribed by the Japan Oil Chemists'Society ${ }^{11)}$ using Rancimat 679 (Metrohm Japan Ltd., Tokyo). The analysis conditions were heating at $90^{\circ} \mathrm{C}$ and airflow under $20 \mathrm{~L} / \mathrm{h}$. Oxidation stability was expressed as the relative induction period based on perilla oil (1.0).

\subsection{Evaluation of heating oxidation stability of oils}

Perilla oil, Ln2:1, Ln1:1 and their interesterified oils (1 g) were placed in separate test tubes and heated in an oil bath at $180^{\circ} \mathrm{C}$ for $7 \mathrm{~h}$. Then, the fatty acid and TAG molecular species compositions of the heated oils were analyzed as described in following section 2.6 Analysis.

\subsection{Analysis}

2.6.1 Lipid composition

The lipid compositions (TAG, DAG, MAG, and free fatty acids) were determined by thin layer chromatographyframe ionization detector (TLC-FID) analysis. An Iatroscan MK-6s with a silica gel rod S-IV(LSI Medience Corporation, Tokyo, Japan)was used, and a mixture of benzene-chloroform-acetic acid (35:15:1, v/v) was used as the development solvent.

2.6.2 Fatty acid composition

Fatty acid constituents of TAG were methyl-esterified using hydrochloric acid /methanol, as described by Jham et $a l{ }^{12)}$ and subjected to gas chromatography (GC), in an 
GC-17A (Shimadzu, Kyoto, Japan) equipped with a flame ionization detector and a fused silica capillary column, HR-SS-10 (0.25 mm $\times 25 \mathrm{~m}$; Shinwa Chemical Industries. Ltd., Kyoto, Japan). The temperature of both injector and detector were $250^{\circ} \mathrm{C}$. Helium at $65 \mathrm{kPa}$ was used as the carrier gas. The column temperature was programmed as $125^{\circ} \mathrm{C}, 3 \mathrm{~min} \rightarrow 15^{\circ} \mathrm{C} / \mathrm{min} \rightarrow 170^{\circ} \mathrm{C}, 0 \mathrm{~min} \rightarrow 2^{\circ} \mathrm{C} / \mathrm{min} \rightarrow 186^{\circ} \mathrm{C}$, $1 \mathrm{~min} \rightarrow 14^{\circ} \mathrm{C} / \mathrm{min} \rightarrow 200^{\circ} \mathrm{C}, 5 \mathrm{~min}$.

2.6.3 FA composition of $s n-2$ position of TAG

Oil $(1 \mathrm{~g})$ was dissolved in ethanol $(4 \mathrm{~mL})$ followed by addition of 4,000 PLU of Novozym $435^{\circledR}$. The ethanolysis reaction was conducted with $300 \mathrm{rpm}$ at $35^{\circ} \mathrm{C}$ for $3 \mathrm{~h}$, and the reaction was terminated by filtering the enzyme out of solution. After evaporating the reaction mixture, TAG, DAG, MAG and fatty acid ethyl ester fractions were separated using Florisi ${ }^{\circledR}$ (containing $7 \%$ of water) column chromatography. The TAG, DAG and fatty acid ethyl ester fractions were eluted using hexane-diethyl ether $(1: 1, \mathrm{v} / \mathrm{v})$, subsequently, the MAG fraction was eluted using methanol. The fatty acid compositions of MAG were measured as described in Section 2.6.2. This method was carried out based on the unique character of Novozym $4355^{\oplus}$ showing $s n-1,3$ positional specificity in ethanolysis ${ }^{13)}$.

2.6.4 TAG molecular species composition

The composition of TAG molecular species was analyzed using high performance liquid chromatography (HPLC) equipped with a reversed phase column Crest Pak C18S $(4.6 \times 150 \mathrm{~mm}$; JASCO Corp., Tokyo $)$, a refractive index detector(RID-10A, Shimadzu), and an integrator (Chromatopac C-R8, Shimadzu). The mobile phase was a mixture of acetone-acetonitrile $(1: 1, \mathrm{v} / \mathrm{v})$, and the flow rate was 0.8 $\mathrm{mL} / \mathrm{min}$. TAG molecular species were identified using equivalent carbon number (ECN) and theoretical carbon number (TCN) of TAGs as described in the literature ${ }^{14,15)}$. Because perilla oil contains palmitic acid $(\mathrm{P})$, stearic acid $(\mathrm{S})$, oleic $\operatorname{acid}(\mathrm{O})$ and linoleic $\operatorname{acid}(\mathrm{L})$ in addition to $\mathrm{Ln}$,
TAG with ECN 36 was defined as 3Ln-TAG(i.e., LnLnLn), TAGs with ECN's of 38 or 40 were defined as $2 \mathrm{Ln}-\mathrm{TAG}$ (i.e., LnLnL, LnLnO, LnLnP etc.), TAGs with ECN's of 42, 44 or 46 (i.e., LnLO, LnOO, LnSL etc.) were defined as 1Ln-TAG, and TAGs having no Ln were defined as OLn-TAG.

\section{RESULTS AND DISCUSSION}

3.1 Fatty acid compositions and TAG molecular species compositions of perilla oil, palm oil, Ln2:1, and Ln1:1

Fatty acid compositions and TAG molecular species compositions of oils used in this study are summarized in Table 1. Perilla oil contained $61.1 \% \mathrm{Ln}$ in total, and the content of $\mathrm{Ln}$ at the $s n-2$ position of TAG was $66.7 \%$. Contents of 3Ln-TAG, 2Ln-TAG, and 1Ln-TAG were 38.7, 40.3, and $21.0 \%$, respectively. No OLn-TAG was found. In contrast, the main fatty acids present in palm oil were palmitic $\operatorname{acid}(\mathrm{C} 16: 0(\mathrm{P}), 44.0 \%)$, oleic acid (C18:1(O), 40.6\%), and linoleic acid (C18:2:(L), 11.3\%), -while no Ln was found. The $3 \mathrm{~L}-\mathrm{TAG}$ content was $0 \%$ and that of OL-TAG was $69.5 \%$. Fatty acid and TAG molecular species compositions of the blended perilla and palm oils, Ln2:1 and Ln1:1, were dependent on their blending proportions.

\subsection{Interesterified perilla oil with Lipozyme $\mathrm{RM}-\mathrm{IM}^{\circledR}$ and their oxidation stabilities}

First, perilla oil was interesterified using Lipozyme $\mathrm{RM}^{\mathrm{IM}}{ }^{\circledast}$ to produce P-1, P-2, and P-3. Because they were prepared by the $s n-1,3$ positional interesterification, their fatty acid compositions were almost the same as that of perilla oil, including at the $s n-2$ and $s n-1,3$ positions of the oils (Fig. 1A-C). In contrast, the 3Ln-TAG content changed in the following order: perilla oil (38.7\%), P-1 (28.9\%), P-2 (18.0\%), and P-3 (14.5\%), suggesting that Ln at the $s n-1,3$ position of 3Ln-TAG in perilla oil was interesterified with

Table 1 Fatty acid compositions and TAG compositions of oils used in this study.

\begin{tabular}{|c|c|c|c|c|c|c|c|c|}
\hline \multirow[b]{2}{*}{ Fatty acid composition (\%) } & \multicolumn{2}{|c|}{ perilla oil } & \multicolumn{2}{|c|}{ palm oil } & \multicolumn{2}{|c|}{$\operatorname{Ln} 2: 1^{*}$} & \multicolumn{2}{|c|}{$\operatorname{Ln} 1: 1^{*}$} \\
\hline & total & $s n-2$ & total & $s n-2$ & total & $s n-2$ & total & $s n-2$ \\
\hline C 16:0 (P) & 8.0 & 0.8 & 44.0 & 10.1 & 20.8 & 2.6 & 25.4 & 3.3 \\
\hline C 18:0 (S) & 1.7 & 0 & 4.1 & 0 & 2.0 & 0 & 2.9 & 0 \\
\hline C 18:1 (O) & 15.6 & 15.9 & 40.6 & 68.0 & 24.3 & 34.8 & 31.9 & 47.8 \\
\hline C 18:2 (L) & 13.6 & 16.6 & 11.3 & 21.9 & 15.4 & 21.6 & 11.8 & 18.8 \\
\hline C $18: 3(\operatorname{Ln})$ & 61.1 & 66.7 & 0 & 0 & 37.9 & 41.0 & 28.0 & 30.1 \\
\hline \multicolumn{9}{|l|}{ TAG composition (\%) } \\
\hline 3Ln-TAG & \multicolumn{2}{|c|}{38.7} & \multicolumn{2}{|c|}{0} & \multicolumn{2}{|c|}{27.6} & \multicolumn{2}{|c|}{20.5} \\
\hline 2Ln-TAG & \multicolumn{2}{|c|}{40.3} & \multicolumn{2}{|c|}{4.5} & \multicolumn{2}{|c|}{30.6} & \multicolumn{2}{|c|}{20.2} \\
\hline 1Ln-TAG & \multicolumn{2}{|c|}{21.0} & \multicolumn{2}{|c|}{26.0} & \multicolumn{2}{|c|}{18.5} & \multicolumn{2}{|c|}{22.3} \\
\hline OLn-TAG & \multicolumn{2}{|c|}{0} & \multicolumn{2}{|c|}{69.5} & \multicolumn{2}{|c|}{23.3} & \multicolumn{2}{|c|}{36.0} \\
\hline
\end{tabular}

* blend oils of perilla and palm oils; Ln2:1, perilla oil : palm oil $=2: 1(\mathrm{w} / \mathrm{w})$ and $\operatorname{Ln} 1: 1$, perilla oil : palm oil $=1: 1(\mathrm{w} / \mathrm{w})$ 
(A) Total fatty acid composition

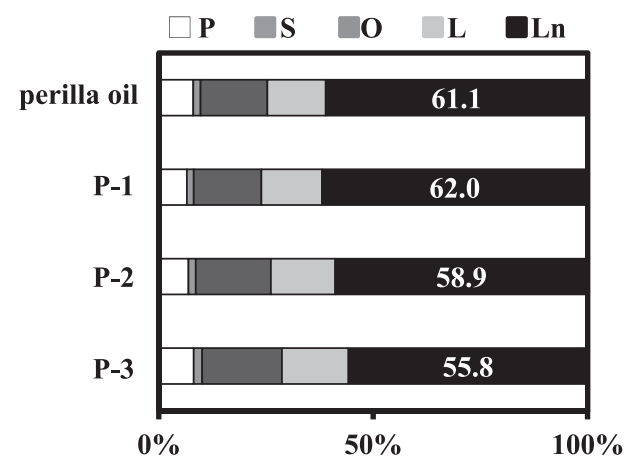

(B) Fatty acid compositions at $s n-2$ position

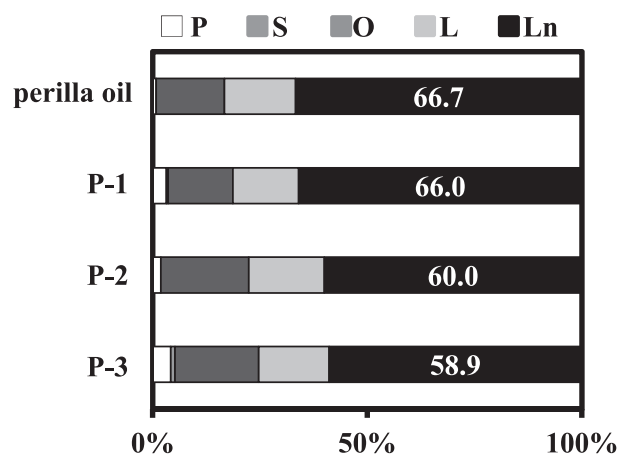

(C) Fatty acid compositions at $s n-1,3$ position

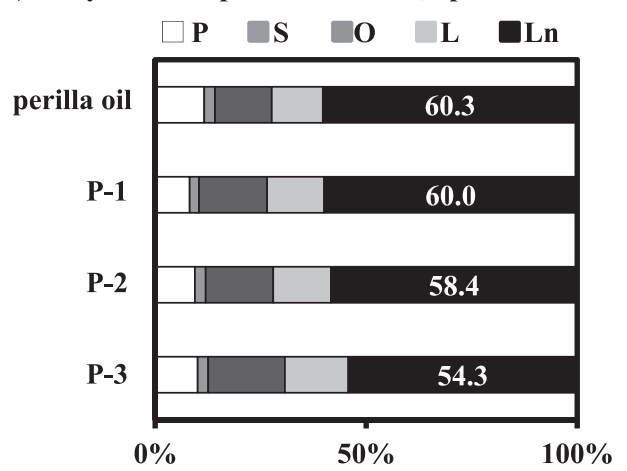

(D) TAG molecular species compositions

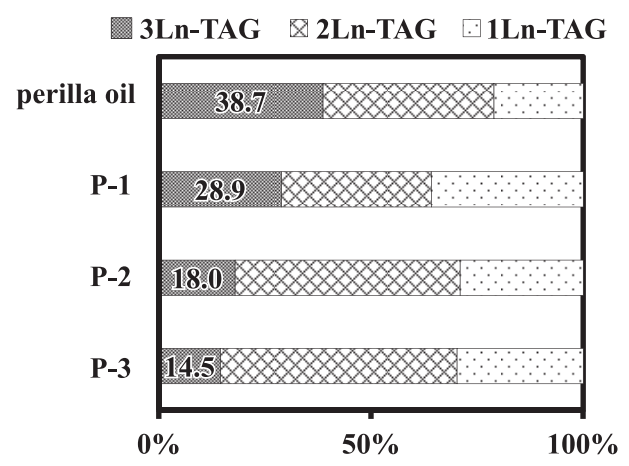

Fig. 1 Fatty acid compositions and TAG molecular species compositions of perilla oil and its Lipozyme RM-IM ${ }^{\circledR}-$ interesterified oils (P-1, P-2 and P-3).

other fatty acids at the $s n-1,3$ position of other TAGs (Fig. 1D). Furthermore, we confirmed that P-1, P-2, and P-3 were oils with the same fatty acid compositions as perilla oil but with the different TAG molecular species compositions.

The relative induction periods of perilla oil, P-1, P-2, and P-3 were 1.0, 1.2, 1.3, and 1.5, respectively (Fig. 2). The relative induction period was dependent on the content of 3Ln-TAG; that is, perilla oil $<\mathrm{P}-1<\mathrm{P}-2<\mathrm{P}-3$. In particular, the 3Ln-TAG content of P-3 was 1.5-fold higher than that of perilla oil. This result indicates that the oxidation stability of oils was strongly affected by the content of 3Ln-TAG. However, the actual induction periods (1.9-2.9 h) were too short to evaluate the dependence precisely. To clarify this, interesterified oils with lower Ln content were prepared from Ln2:1 and Ln1:1, and we evaluated their oxidation stabilities.

\subsection{Oxidation stability of interesterified blended oils using Lipozyme RM-IM ${ }^{\circledast}$}

Blended oils (Ln2:1 and Ln1:1)were interesterified for 4 h using Lipozyme RM-IM ${ }^{\circledast}$ to prepare oils with a lower content of 3Ln-TAG. The fatty acid compositions of inter-

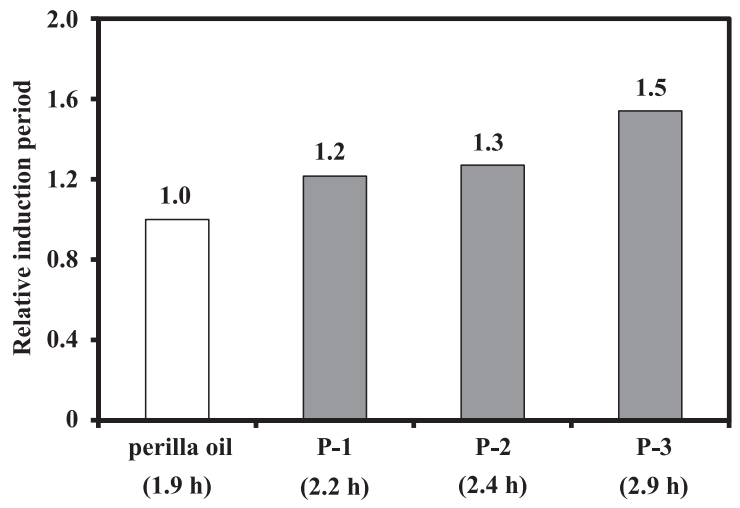

Fig. 2 Oxidation stability of perilla oil and its Lipozyme RM-IM ${ }^{\circledR}$-interesterified oils (P-1, P-2 and P-3). CDM conditions: $90^{\circ} \mathrm{C}$ of heating temperature and $20 \mathrm{~L} / \mathrm{h}$ of air stream. Values in parenthesis is induction period measured.

esterified Ln2:1 and Ln1:1 were the same as those of preinteresterified Ln2:1 and Ln1:1, including total, at the $s n-2$ and $s n-1,3$ positions of the oils (data not shown). The 3Ln-TAG content of Ln2:1 decreased interesterification 


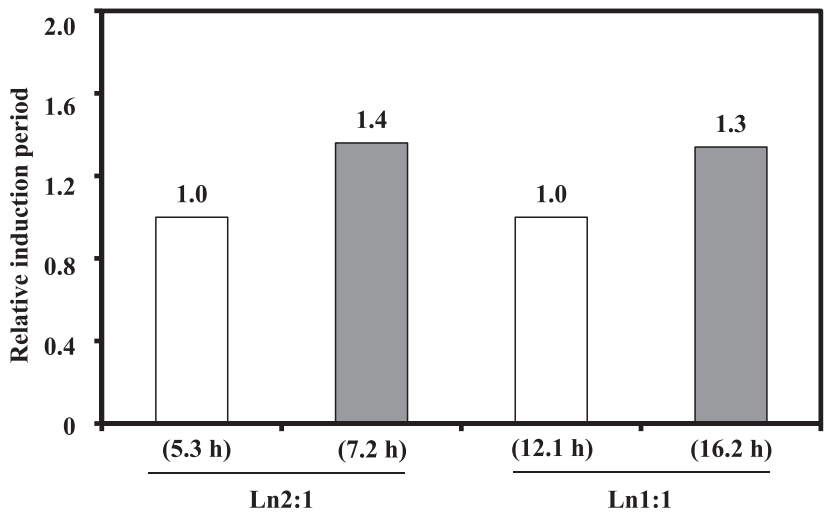

Fig. 3 Oxidation stability of Lipozyme RM-IM ${ }^{\circledR}$ interesterified oils. $\mathrm{CDM}$ conditions: $90^{\circ} \mathrm{C}$ of heating temperature and $20 \mathrm{~L} / \mathrm{h}$ of air stream. Values in parenthesis is induction period measured. Open column shows relative induction period of oils before interesterification and closed column is that of interesterified oils.

from $27.6 \%$ to $5.4 \%$, and that of $\operatorname{Ln} 1: 1$ decreased from $20.5 \%$ to $2.5 \%$. The relative induction period, measured by CDM test of interesterified Ln2:1 was 1.4 times longer than that of Ln2:1. Furthermore, that of Ln1:1 was 1.3 times longer than Ln1:1 (Fig. 3). As in the case of perilla oil (c.f. Section 3.2), this indicates that 3Ln-TAG content strongly influenced oxidative stability of that oils.

In addition, heating the oxidation stabilities of Ln-TAGs of interesterified Ln2:1 and Ln1:1 were also evaluated(Fig. 4). The residual ratio, expressed as the relative residue (content of $1 \mathrm{Ln}-\mathrm{TAG}=100 \%$ ), of 3Ln-TAG and $2 \mathrm{Ln}-\mathrm{TAG}$ of interesterified Ln2:1 were $23.3 \%$ and $36.8 \%$, respectively, and that of Ln1:1 was $12.7 \%$ and $30.2 \%$, respectively.

From these results, we found that the oxidation stability of Ln-TAGs was $3 \mathrm{Ln}-\mathrm{TAG}<2 \mathrm{Ln}-\mathrm{TAG}<1 \mathrm{Ln}-\mathrm{TAG}$.

(A)

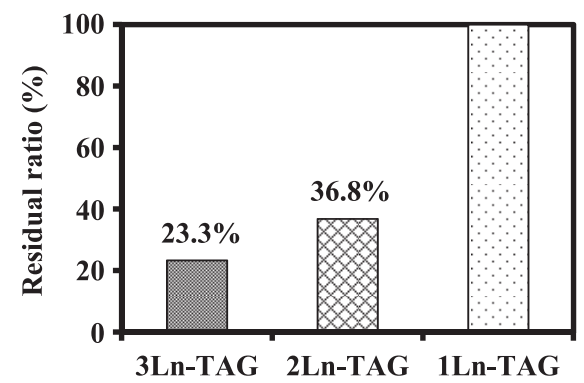

\subsection{Interesterified blended oils with Lipase OF $^{\circledR}$}

To investigate the effect of fatty acid composition at the $s n-2$ position on the oxidation stability of TAG molecule, Ln2:1 and Ln1:1 were interesterified for $48 \mathrm{~h}$ using positionally non-specific Lipase $\mathrm{OF}^{\circledR}$ to prepare oils having the same fatty acid composition but with different TAG composition. Results are shown in Fig. 5. The total fatty acid compositions of blended and interesterified oils were the same (Fig. 5A); in contrast, the fatty acid compositions at $s n-2$ and $s n-1,3$ positions of the interesterified oils were different from those of the pre-interesterified blended oils (Figs. 5B and C), resulting in different TAG compositions (Fig. 5D). In contrast with the results obtained using Lipozyme RM-IM ${ }^{\circledR}$, the fatty acid composition at the $s n-2$ position was changed in both blended oils formed using Lipase $\mathrm{OF}^{\circledR}$-mediated interesterification. The content of unsaturated fatty acids $(\mathrm{O}+\mathrm{L}+\mathrm{Ln})$ at the $s n-2$ position decreased on interesterification(Fig. 5B). Accordingly, unsaturated fatty acid content at the $s n-1,3$ positions increased on interesterification (Fig. 5C).

\subsection{Effect of TAG molecular species composition on oxi- dation stability}

Finally, we discuss the effect of the composition of TAG molecular species on oxidation stability. Figure 6 shows a comparison of the relative induction periods of oils interesterified with Lipase $\mathrm{OF}^{\circledR}$ and Lipozyme RM-IM ${ }^{\circledR}$. Oxidation stability of Lipozyme RM-IM ${ }^{\circledR}$-interesterified Ln2:1, which had 1.4 times the relative induction period of the unesterified oil, was slightly longer than that of Lipase $\mathrm{OF}^{\circledR}$-interesterified Ln2:1, which had 1.3 times the relative induction period: however for both the 3Ln-TAG contents were the same (3Ln-TAG contents of Lipozyme RM-IM ${ }^{\circledR}$ interesterified Ln2:1 and that of Lipase $\mathrm{OF}^{\circledR}$-interesterified Ln2:1 were $5.4 \%$ and $7.3 \%$, respectively). Here, fatty acid compositions of unsaturated fatty acids $(\mathrm{O}+\mathrm{L}+\mathrm{Ln})$ at the $s n-2$ position decreased after Lipase $\mathrm{OF}^{\circledR}$-mediated inter-

(B)

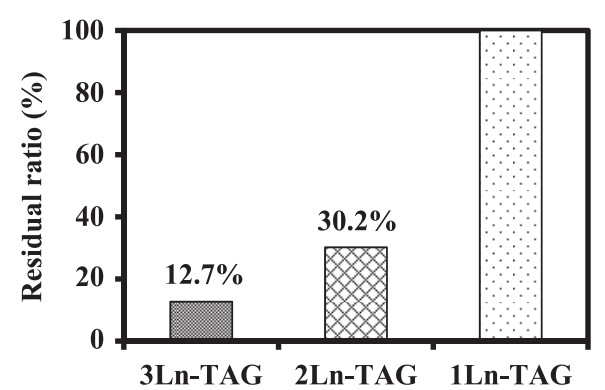

Fig. 4 Residual ratio of Ln-TAGs in Lipozyme RM-IM ${ }^{\circledR}$-interesterified oils. Heating conditions: $180^{\circ} \mathrm{C}$ of heating temperature and $7 \mathrm{~h}$ of heating period. Residual ratio was shown as relative residue (content of $1 \mathrm{Ln}-\mathrm{TAG}=$ $100 \%$ ). A: residual ratio of Ln-TAGs of interesterified Ln2:1, B: residual ratio of Ln-TAGs of interesterified Ln $1: 1$. 
(A) Total fatty acid composition

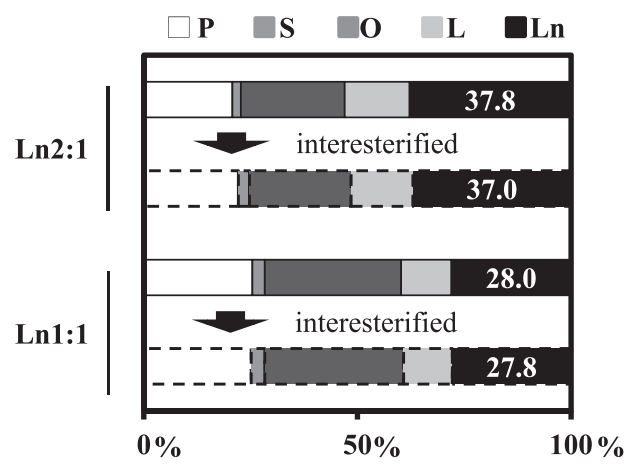

(C) Fatty acid compositions at $s n-1,3$ position

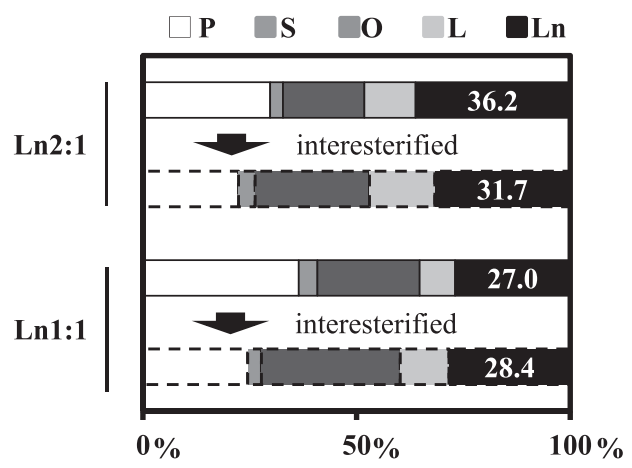

(B) Fatty acid compositions at sn-2 position

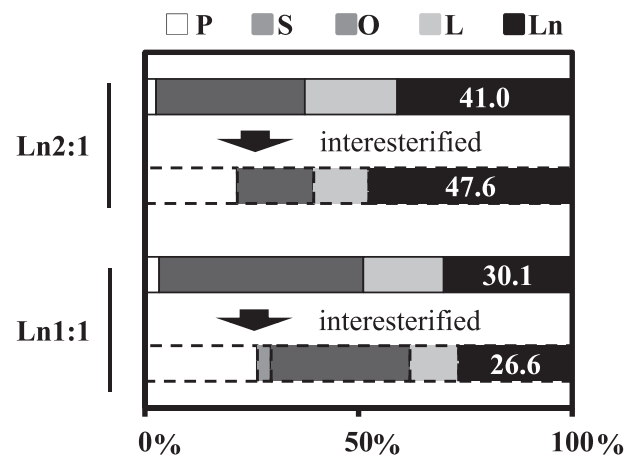

(D) TAG molecular species compositions

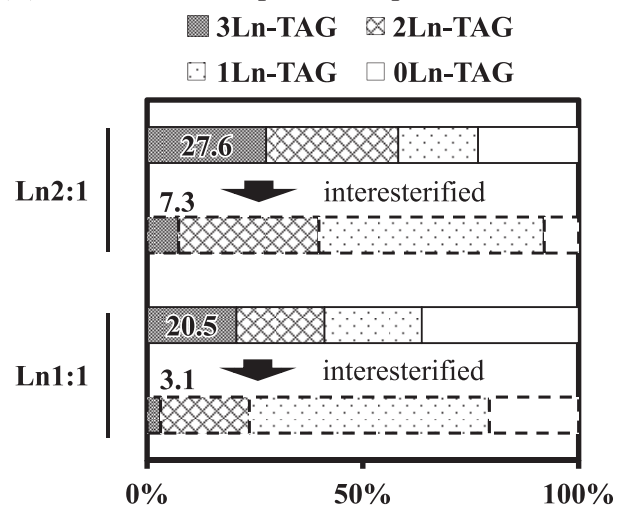

Fig. 5 Fatty acid compositions and TAG compositions of blended oil (Ln2:1 and Ln1:1) and its lipase $\mathrm{OF}^{\circledR}-$ interesterified oils.

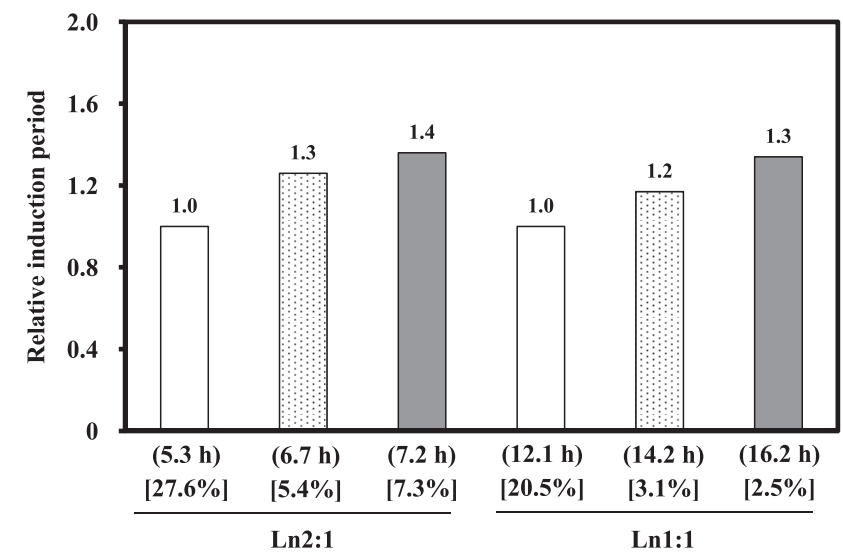

Fig. 6 Comparison of relative induction period of oils obtained from Lipase $\mathrm{OF}^{\circledR}$ and Lipozyme RM$\mathrm{IM}^{\circledR}$. CDM conditions: $90^{\circ} \mathrm{C}$ of heating temperature and $20 \mathrm{~L} / \mathrm{h}$ of air stream. Values in upper parenthesis is induction period measured and lower one shows the content of Ln of the oil. $\square$ :pre-interesterification. $:$ :interesterified using Lipase $\mathrm{OF}^{\circledR} . \square$ : interesterified using Lipozyme RM-IM ${ }^{\circledR}$ (data were referenced from Fig. 4). esterification (Fig. 5B). Furthermore that of at $s n-1,3$ position increased (Fig. 5C). Similar results were obtained in the case of Ln1:1. These results indicate that, when fatty acid compositions and TAG compositions are the same, the oxidation stabilities of oils containing TAG with unsaturated fatty acid at the $s n-2$ position was higher those with unsaturated fatty acids at the $s n-1,3$ positions. Miyashita et $a l$., reported opposing results; 2Ln-TAG was less stable to oxidation when Ln was at the $s n-1,2$ (or $-2,3$ ) positions compared to the $s n-1,3$ glycerol positions in autoxidation tests $\left(40^{\circ} \mathrm{C}\right)^{10)}$. Our study was conducted under heating conditions $\left(90^{\circ} \mathrm{C}\right)$. In the future, we with to clarify why the oxidation behavior of Ln-TAG changes on changing the oxidation conditions.

Because of the improvement in the degree of relative induction period on decreasing the content of 3Ln-TAG was greater than that of positional change of the unsaturated fatty acid, the influence of the content of 3Ln-TAG on oxidation stability of oils greater than the positional effect.

\section{CONCLUSION}

By comparing the oxidation stabilities of oils rich in Ln 
having the same fatty acid compositions but with different composition of TAG molecular species, the following results were obtained. I. The oxidation stability of Ln-TAGs was in the following order: $3 \mathrm{Ln}-\mathrm{TAG}<2 \mathrm{Ln}-\mathrm{TAG}<1 \mathrm{Ln}-$ TAG. II. The oxidation stability of TAG containing unsaturated fatty acids at the $s n-2$ position was higher than those containing unsaturated fatty acids at the $s n-1,3$ position. III. The influence of 3Ln-TAG content against oxidation of oils is greater than the effect of positional substitution of unsaturated fatty acids in TAG. From these results, oxidation stability of oils rich in Ln, such as perilla oil and linseed oil, will improve on lowering the 3Ln-TAG content using a $s n-1,3$ positional lipase.

\section{References}

1) Bailey, A. E. "Industrial Oil and Fat Products", Interscience (1964).

2) Gunstone, F. D.; Padley, F. B. Glyceride studies. part III. The component glycerides of five seed oils containing linolenic acid. J. Am. Oil Chem. Soc. 42, 957-961 (1965).

3) Chung, K. H.; Hwang, H. J.; Shin, K. O.; Jeon, W. M.; Choi, K. S. Effects of perilla oil on plasma concentrations of cardioprotective (n-3) fatty acids and lipid profiles in mice. Nutr. Res. Pract. 7, 256-261 (2013).

4) Wada, S.; Koizumi, C. Influence of the position of unsaturated fatty acid esterified glycerol on the oxidation rate of triglyceride. J. Am. Oil Chem. Soc. 60, 1105-1109 (1983).

5) Kimoto, H.; Endo, Y.; Fujimoto, K. Influence of interesterification on the oxidative stability of marine oil triacylglycerols. J. Am. Oil Chem. Soc. 71, 469-473 (1994).

6) Chakra, W.; Claudio, C.; Peter, W.; Peter, F.; Benjamin, F.; Neeranat, T.; Patrick, P. Docosahexaenoic acid is more stable to oxidation when located at the $s n-2$ position of triacylglycerol compared to sn-1(3). J. Am. Oil Chem. Soc. 85, 543-548(2008).

7) Yamamoto, Y.; Imori, Y.; Hara, S. Oxidation behavior of triacylglycerol containing conjugated linolenic acids in sn-1 (3) or sn-2 position. J. Oleo Sci. 63, 31-37(2014).

8) Neff, W. E.; Frankel, E. N.; Miyashita, K. Autoxidation of polyunsaturated triacylglycerols. I. Trilinoleoyglycerol. Lipids 25, 33-39 (1990).

9) Frankel, E. N.; Neff, W. E.; Miyashita, K. Autoxidation of polyunsaturated triacylglycerols. II. Trilinolenoyglycerol. Lipids 25, 40-47(1990).

10) Miyashita, K.; Frankel, E. N.; Neff, W. E.; Awl, R. A. Autoxidation of polyunsaturated triacylglycerols. III. Synthetic triacylglycerol containing linoleate and linolenate. Lipids 25, 48-53(1990).

11) Standard Method for the Analysis of Fats, Oils and Related Materials (Japan Oil Chem. Soc., ed.), Conductometric Determination Method, 2.5.1.2-2013.

12) Jham, G. N.; Teles, F. F. F.; Campos, L. G. Use of aqueous $\mathrm{HCI} / \mathrm{MeOH}$ as esterification reagent for analysis of fatty acids derived from soybean lipids. J. Am. Oil Chem. Soc. 59, 132-133(1982).

13) Irimescu, R.; Furihata, K.; Hata, K.; Iwasaki, Y.; Yamane, T. Utilization of reaction medium-dependent regiospecificity of Candida antarctica Lipase (Novozym435) for the synthesis of 1,3-dicapryloyl2-docosahexaenoyl (or eicosapentaenoyl) glycerol. $J$. Am. Oil Chem. Soc. 78, 285-289(2001).

14) Plattner, R. D.; Spencer, G. F.; Kleiman, R. Triglyceride separation by reverse phase high performance liquid chromatography. J. Am. Oil Chem. Soc. 54, 511-515 (1977).

15) El-Hamdy, A. H.; Perkins, E. G. High performance reversed phase chromatography of natural triglyceride mixtures: critical pair separation. J. Am. Oil Chem. Soc. 58, 867-872(1981). 